\title{
ECOS DE VIOLA NO SAMBA DE TAMBORETE
}

\section{ECHOES OF VIOLA IN SAMBA OF TAMBORETE}

Resumo: Quais os impactos do processo de patrimonialização do samba de roda do Recôncavo baiano em manifestações que lhe guardam proximidade? Objetivando uma reflexão acerca deste questionamento, o presente artigo $^{2}$ toma o samba de véio realizado na comunidade do Rodeadouro, Juazeiro-BA, como objeto e seus praticantes como sujeitos da pesquisa, constituindo os impactos operados pelo processo de patrimonialização do samba do Recôncavo no samba do Rodeadouro como problema de pesquisa. Para tanto, tomamos as perspectivas etnográficas e o ponto de vista da história oral, a partir da qual os relatos e falas de nossos sujeitos de pesquisa são entendidos como fontes históricas.

Palavras-Chave: Samba de Véio, Patrimonialização, Política cultural, Cultura negrodiaspórica.

\begin{abstract}
What are the impacts of the heritage process of the Bahian Reconcavo Area's "samba de roda" in demonstrations that can be seen by you in your neighborhood ? For a fair reflection of this questioning, this article takes the samba de véio held in Rodeadouro community , Juazeiro-BA, as an object, while its practitioners were held as research subjects, constituting the impacts operated by patrimonialization process of Recôncavo samba upon Rodeadouro samba as a research problem. For this purpose, we take the ethnographic perspectives and the point of view of oral history, from which the reports and speeches of our research subjects are understood as historical sources.
\end{abstract}

Keywords: Samba de Véio, Patrimonialization, Cultural policy, Black-diasporic culture.

\footnotetext{
${ }^{1}$ Mestra pelo Programa de Pós-Graduação em Crítica Cultural da Universidade do Estado da Bahia (UNEB). Professora convidada do Departamento de História da Universidade de Pernambuco - UPE campus Petrolina. E-mail: querciaoliveira@gmail.com

${ }^{2}$ Um extrato da dissertação Ecos de Viola no Samba de Tamborete: Jabutinagens às margens do São Francisco (OLIVEIRA, 2013).
} 


\section{PATRIMONIALIZAÇÃO DO SAMBA DE RODA DO RECÔNCAVO BAIANO - O GENOCÍDIO DOS TAMBORES}

Antes de entrarmos na roda do "Samba de Véio", praticando a observação e participação observante sobre nossa manifestação e comunidade campo de estudo, é eminente a necessidade de perpassarmos, mesmo que, rapidamente, a política patrimonial brasileira, em especial a do Estado da Bahia, e o processo de patrimonialização do samba de roda do Recôncavo baiano. Afinal de contas, quais os desejos subjacentes à candidatura do samba de roda ao título de "patrimônio cultural da humanidade"? Que forças estiveram em disputa no processo de constituição desta candidatura?

Para visualizarmos a definição da política patrimonial no Brasil e na Bahia, temos que retornar à década de 1930 quando - contemporaneamente - teve lugar a formulação do paradigma da democracia racial, sendo constituído o Serviço do Patrimônio Histórico e Artístico Nacional (SPHAN). Trazendo a concepção de patrimônio histórico, cunhada na França, e tendo como objetivo a identificação de um patrimônio cultural brasileiro que se afirmasse diferenciado em relação ao europeu e ao estadunidense, o SPHAN participou do processo de consolidação de uma estrutura burocrático-cultural do Estado brasileiro, que visava a substituição de antigas e descontínuas relações entre Estado e cultura por políticas públicas, ou seja, ações planejadas e implementadas, com perspectivas de perenidade. Neste âmbito, inserem-se as políticas de preservação do patrimônio nacional. Preocupadas, inicialmente, com a preservação e restauração de monumentos que guardavam interesse nacional, fosse de caráter religioso, civil ou militar, as políticas patrimonialistas brasileiras se voltavam para o estudo, a documentação e a divulgação de bens culturais isolados, o que as assemelharia às políticas museológicas.

A partir da segunda metade da década de 1960, quando o Serviço já havia sido transformado em Instituto do Patrimônio Histórico e Artístico Nacional (IPHAN), as políticas do patrimônio no Brasil estiveram marcadas pela tentativa de conciliar a preservação de valores "tradicionais" e o desenvolvimento econômico das regiões, o que gerou uma vinculação da área ao turismo, afinal de contas, "o fluxo turístico era visto como a melhor forma econômica para a conservação e a valorização do patrimônio cultural e natural” (SANTOS, 2005:79). 
Para tanto, era preciso conformar na nação um ideal de patrimônio e cultura brasileira. Assim, foi recomendada aos estados - e às suas secretarias de cultura - uma articulação com os meios de comunicação de massa que garantisse a veiculação e propagação do patrimônio nacional, ao mesmo tempo em que este figurava como conteúdo escolar (SANTOS, 2005; CARMO, 2009).

$\mathrm{Na}$ Bahia, de forma específica, esse turismo cultural foi constituído entre definições discursivas do patrimônio nacional e da "tradição afro-brasileira", como diria Santos (2005), ou negro-diaspórica, como preferimos. Os bens a serem visitados pelo turista e, consequentemente, preservados pelas políticas patrimoniais, contudo, não puderam se limitar ao conjunto arquitetônico e monumental do Estado. Havia uma imagem do cotidiano a ser apreendida, uma vivência cultural que deveria ser realizada, uma baianidade a ser contemplada pelos roteiros turísticos. Construiu-se, assim, a concepção da Bahia como nação cultural distinta, na linguagem e na religião, do restante do país. Esta singularidade, por sua vez, poderia ser percebida "nas distinções das origens africanas com a cultura ocidental. A docilidade, o ritmo, a sensualidade, a malandragem, a capoeira e a culinária seriam tanto os elementos básicos desse contraste quanto o que imprimiria as características próprias do "jeito baiano" (SANTOS, 2005:88, grifos do autor).

Entre o "contraste negro" e a "docilidade baiana", contudo, podemos identificar a mediação do Estado, engajado na constituição de uma imagem morena para a Bahia. Assim, e servindo-se das alianças feitas com os grandes meios de comunicação de massa, em especial a TV, foi alardeada uma democracia racial também singular: dentro do racialmente democrático Brasil, havia uma nação cultural diferenciada cuja democracia havia sido construída de forma especialmente emotiva, pulsante e festiva. Tendo sido expropriado de seu potencial simbólico de resistência e contestação ao processo de exploração do 'homem pelo homem', o complexo cultural negro-diásporico ${ }^{3}$ foi constituído como patrimônio cultural baiano e sobre ele operaram as lógicas do capital, a mediação monetária e a afirmação discursiva da harmonia racial.

\footnotetext{
${ }^{3}$ A partir de proposições de Stuart Hall (2003), tomamos o termo "negro-diaspórico" como sinalizador de um complexo cultural construído em um não lugar geográfico cuja potência de subversão de modelos culturais orientados à nação é, concomitantemente, latente e manifesta e diretamente relacionado à condição racial negra.
} 
A partir da segunda metade da década de 1960, durante o período da ditadura militar, as políticas patrimoniais nacionais estiveram voltadas para a integração e a uniformização comportamental brasileira. Afirmando a centralidade da cultura popular, o Estado ditatorial na Bahia visava, ainda, a proteção da "vida cotidiana baiana" já constituída em bem cultural, ameaçado pelos novos padrões trazidos pela Indústria Cultural. Como meta para o desenvolvimento econômico, instaurou-se a continuidade das atividades turísticas. Ao complexo cultural negro, por sua vez, foi destinado o mesmo tratamento do regime político anterior, constituindo-o como bem cultural baiano. Em 1985, no processo de abertura e redemocratização política do Brasil, como vimos acima, o Estado operou uma tentativa de manutenção da circunscrição das questões do negro ao âmbito cultural. A mestiçagem e a harmonia racial, por sua vez, fosse como modelos aplicados ou almejados, continuaram a figurar como centro do discurso político-cultural e identitário brasileiro.

Em 1988, com a promulgação da nova Constituição, o patrimônio imaterial teve sua proteção regulamentada. No artigo 216, tivemos definido o caráter material e imaterial do patrimônio nacional, tomado de forma individual ou coletiva, que portasse referência à identidade, à ação ou à memória dos diferentes grupos formados pela sociedade brasileira. Incluemse, assim, as formas de expressão; os modos de criar, fazer e viver; as criações científicas, artísticas e tecnológicas; as obras, objetos, documentos, edificações e demais espaços destinados às manifestações artísticas; os conjuntos urbanos e sítios de valor histórico, paisagístico, artístico, arqueológico, paleontológico, ecológico e científico. Como já era de se esperar, a proteção e a promoção do patrimônio se constituiu como dever do Estado em colaboração com a comunidade. Como meios para tanto, foram estabelecidos os inventários, registros, vigilância, tombamento, assim como outras formas de acautelamento e preservação.

O processo de regulamentação deste artigo, contudo, só teve início uma década depois, com a criação do Grupo de Trabalho Patrimônio Imaterial (GTPI). Também nesta perspectiva, no ano de 2000, através do Decreto n. 3.551, foi instituído o Programa Nacional de Patrimônio Imaterial e o Registro de Bens Culturais de Natureza Imaterial, no qual foram definidas as quatro categorias e os livros de registro para o patrimônio imaterial: os saberes - definidos como os conhecimentos e modos de fazer enraizados no cotidiano das comunidades; as celebrações - que abarcavam os rituais e festas que marcam a vivência coletiva do trabalho, reli- 
Pontos de Interrogação, v. 3, n. 2, jul./dez. 2013

Revista do Programa de Pós-Graduação em Crítica Cultural

Universidade do Estado da Bahia (UNEB), Campus II - Alagoinhas - BA

giosidade, entretenimento e outras práticas da vida social; as formas de expressão - manifestações literárias, musicais, plásticas, cênicas e lúdicas; e os lugares - mercados, feiras, santuários, praças e demais espaços onde se concentrem e se reproduzam práticas culturais coletivas.

No ano de 2002, o Brasil procedeu a seu primeiro registro do patrimônio imaterial e em 2003, quando a UNESCO lançou a segunda listas de bens inscritos como Patrimônio Oral e Imaterial da Humanidade, a arte gráfica dos índios Wajãpi se tornou a primeira representante brasileira na lista. No ano seguinte, a UNESCO recebeu novas candidaturas ao título. Como representante do Brasil, foi inscrito o samba de roda do Recôncavo baiano.

Entrecruzando as definições de patrimônio ofertadas pela literatura da área, os históricos referentes ao tratamento destinado ao complexo negro-diaspórico no Brasil - no qual se situa o das festas negras, seus tambores e o próprio samba - e uma interpretação do processo de candidatura e patrimonialização do samba de roda do Recôncavo baiano, podemos perceber o subjacente desejo de patrimonialização do samba realizado no Rio de Janeiro, tido como nacional. Objeto primeiro da intenção patrimonialista, o samba nacional, como exposto acima, não foi candidatado por questões impostas pela UNESCO. Os argumentos que embasaram a candidatura internacional do samba do Recôncavo, e mesmo o seu registro nacional, no entanto, estiveram sempre atrelados ao intuito de constituí-lo como matriz folclórica do samba carioca.

Reatualizando a proposta patrimonial do Estado Novo na qual o samba carioca, atrelado à indústria cultural, representaria o símbolo de unificação nacional, enquanto o samba da Bahia se configurava como representante regional a ser assimilado pelos maestros e compositores da música clássica, tendo suas referências sempre presas à sua localização geográfica. Neste contexto, uma diversidade de sambas realizados em outros estados brasileiros foram estrategicamente esmaecidos, reforçando-se no imaginário coletivo "o samba" e sua versão matricial, ainda não urbanizada, feito na Bahia.

Numa segunda perspectiva, podemos apontar os processos de apropriação e assimilação discursiva pelos quais passou o samba do Recôncavo para a constituição de uma manifestação mestiça. Mais uma atualização do que fora proposto pela política patrimonial do Estado Novo, a postura assumida pelo IPHAN (2006) destaca, em meio ao complexo cultural que constitui o samba de roda, elementos e imagens que nos vertem a uma manifestação morena, construída a 
partir da interação pacífica entre a cultura africana e a europeia. É assim que, entre os diferentes instrumentos necessários para a realização de uma roda de samba, a viola, em especial, a machete, assumiu uma postura central no texto do Dossiê (LIMA, 2011).

De origem europeia, responsável pela harmonia da música e representante do paradigma patrimonial material, a viola se sobrepôs, no texto do Dossiê, aos tambores, atabaques, pandeiros, às palmas e ao prato e faca - estes três últimos apontados pelo Sr. Bafafá (LIMA, 2003) como únicos instrumentos essenciais ao samba de roda. No plano de salvaguarda, a viola também ganhou atenção especial, sendo proposto o registro do repertório, oficinas de execução e o reestabelecimento da confecção do instrumento. $\mathrm{O}$ estado de contingência no qual o instrumento foi tomado pelo complexo cultural negro-diaspórico, no entanto, não esteve problematizado pelo Dossiê. De acordo com Cássio Nobre (2008), a viola foi adotada no Brasil pelos africanos e seus descendentes como substituta de instrumentos africanos como o pluriarco, o lamelofone e o xilofone, o que nos evidencia a violência da escravidão e o estado de ausência em que o instrumento foi adaptado à prática do samba.

A roda, por sua vez, tão mitificada na história social do samba, foi descrita pelo Dossiê como figurativa, uma vez que "a forma real de disposição dos participantes pode ser antes a de um semicírculo, ou mesmo, a depender do espaço onde acontece o samba, assemelhar-se a um quadrado ou a uma elipse. Como no caso da famosa Távola Redonda [...]” (IPHAN, 2006:36).

Da Távola Redonda? Referência ao conjunto mítico inglês? Por que não à cabaça, objeto que, mesmo assumindo vários formatos, na prática, representa, dentro da mitologia negrodiaspórica, o redondo mundo? Por que não fazer referência à concepção cíclica da energia, que propõe às manifestações religiosas negro-diaspóricas a formação circular? Entre muitas possibilidades de exemplificação, o redator optou pela europeia Távola Redonda, o que nos leva, mais uma vez, a apontar o desejo subjacente de constituir uma manifestação morena na qual coabitem elementos constituidores do nosso mito de fundação.

Implícita também em outros espaços de descrição, a intenção de constituir o samba de roda como uma manifestação baiana mestiça, e não negra, é manifestada, de forma literal, quando, em sua justificativa, o texto do Dossiê contra-argumenta a origem africana atribuída ao samba de roda pelos seus praticantes. Vejamos o texto: 
Essa convicção expressa pelos praticantes do samba é, como já foi visto, corroborada pelos registros históricos. Mas ela não exclui o fato de que o samba de roda é resultado de um processo de trocas interculturais. Sendo uma atividade de afro-descendentes, e exibindo traços culturais de origem africana, ele não deixa de comportar, desde seus primeiros registros históricos, elementos trazidos pelos europeus. (IPHAN, 2006:72-73).

Na sequência, o redator aponta a adoção do prato e da faca, utensílios domésticos de origem europeia; os instrumentos cordofones europeus, como o violão e, novamente, a viola; os cortes estróficos; o ritmo poético; e a língua portuguesa. A presença de tais elementos é, de fato, constatável. A sua utilização argumentativa, contudo, é testemunha de um posicionamento político. Contrapô-las à afirmação de que o samba de roda teria origem africana nos dá indícios do motivo pelo qual a viola, utilizada de forma destacada somente pelos praticantes do samba chula, é tomada como instrumento símbolo do samba de roda do Recôncavo e não os tambores, atabaques ou pandeiros, presentes também na modalidade conhecida como samba corrido. A ausência de problematização das relações raciais brasileiras, também é um índice do paradigma moreno sob o qual o Dossiê está elaborado. Desta forma, as imposições linguísticas que resultam no uso do idioma e das regras poéticas do português, assim como a potencialidade presente no processo de reversão do simbolismo europeu, quando o prato e a faca são constituídos como instrumentos musicais, são tomadas simplesmente como "trocas interculturais".

O esmaecimento dos conflitos, seja por ausência de criticidade, como pondera Lima (2003) quando discute o processo de constituição do samba como gênero musical, seja por adesão consciente ao projeto cultural e patrimonialista conduzido pelo Estado brasileiro, resguarda o genocídio há muito perpetrado contra o complexo negro-diaspórico no país. Se, no final do século XIX, o confronto direto instituído pelos editais de polícia não logrou êxito, a política genocida de assimilação resguardada pelo paradigma da democracia racial, forjada em meio ao movimento modernista, ao desenvolvimento dos meios de comunicação de massa e ao populista Estado Novo, incidiu o primeiro golpe nos tambores negros no samba. Falamos do processo de mediação do Estado, do carnavalesco e do produtor cultural, inserido no seio do samba, transformado em símbolo nacional urbanizado, quando praticado no Rio, e em regional dócil e folclorizado, quando feito na Bahia. 
Mesmo contestado a partir da década de 1950, o paradigma da harmônica e democrática relação racial no Brasil, e todas as pulsões genocidas que lhes são subjacentes, é constantemente reatualizado, sobrevivendo à ditadura militar, ao processo de abertura política e à entrada do Brasil na era das políticas públicas. Neste contexto, o processo de patrimonialização do samba de roda desfere um novo golpe aos tambores do samba, mas, agora, somente no baiano. Implícita à postura política assumida pela relatoria do Dossiê, o paradigma da morenidade brasileira elege as cordas europeias, as trocas interculturais e a posição matricial em relação ao samba nacional como representantes maiores do samba de roda de roda do Recôncavo. Em outras palavras, e parafraseando Santos (2005), o samba de roda do Recôncavo é negro-diaspórico, na origem, mas base para a mestiça nacionalidade, na concepção.

\section{ARRODEANDO PEDRAS}

Segundo seus moradores, a comunidade do Rodeadouro surgiu, em data ainda não precisada, como ponto de apoio para navegantes do Rio São Francisco. Até a década de 1970, quando foi construída a Barragem de Sobradinho para implantação de hidrelétrica, a região de Juazeiro-BA e Petrolina-PE realizava o fluxo de mercadorias através de grandes embarcações apelidadas de "vapores", que trafegavam entre as cidades de Pirapora-MG e JuazeiroBA/Petrolina-PE. Com a construção da barragem, contudo, houve a diminuição do volume de água do Rio, que passou a ter sua vazante regularizada pelas comportas da Companhia Hidrelétrica do São Francisco (CHESF), responsável pela administração da Barragem de Sobradinho, o que dificultou a passagem de grandes embarcações (ADMINISTRAÇÃO DA HIDROVIA DO SÃO FRANCISCO, 2012).

Foi também deste movimento de navegação precedente à construção da barragem que surgiram os nomes homônimos da ilha e da Comunidade. De acordo com D. Ovídia4:

\footnotetext{
${ }^{4}$ Uma das líderes da comunidade, D. Ovídia coordena, entre outros, o processo organizativo de saída do reisado e do samba, atividade antigamente desempenhada por sua tia, a quem acompanhava quando realizou seus primeiros contatos com o Reisado, ainda criança. Da vivência e representação comunitária, advém seu posicionamento e visão conceituais sobre as manifestações e forma de organização do Rodeadouro, sobre as quais porta valiosas informações que nos foram ao longo de nossos questionamentos, generosamente ofertados. Entrevista filmada e fotografada - Juazeiro-BA, 2012.
} 
Quando os barqueiros iam subindo... e aí você vê que aqui mesmo na beira do rio já tem pedra, lá naquela volta [D. Ovídia aponta para ponta da Ilha do Rodeadouro localizada em frente à comunidade do Rodeadouro] tem pedra, as barcas saiam arrodeando as pedras. Aí, quando passavam umas [barcas] pelas outras, que havia acontecido alguma coisa, diziam: 'Lá no arrodeador'. No arrodeador, porque eles saíam arrodeando as pedras para livrar as barcas, aí eles consideravam o nome o arrodeador, que deu origem ao nome Rodeadouro.

O lugar de passagem para navegantes, no entanto, seria, simultaneamente, utilizado como esconderijo de escravizados fugidos, como relata D. Fátima ${ }^{5}$, "os iniciantes vieram através dos negros que aqui se refugiavam. A gente tinha todo aquele processo das navegações, e... aqui, parando para descanso. E, nesse período, aqueles que vinham fugindo, acabavam entrando na comunidade e foram eles os fundadores".

Apontando negros refugiados como fundadores do Rodeadouro, D. Fátima nos dá indícios de que a comunidade possui uma formação quilombola. Sobre este aspecto, D. Ovídia nos conta que "até alguns anos atrás, [os moradores do Rodeadouro] não tinha ideia disso, mas, surgiu aqui o pessoal da CPT [Comissão Pastoral da Terra], né?, que trabalha com a terra, e conseguiu descobrir que aqui tem remanescentes quilombola".

Neste contexto, a fala de D. Ovídia nos alerta para o estado, ainda atual, de invisibilização e esmaecimento do pertencimento sociocultural em que se encontram as comunidades tradicionais, em especial as negras no Brasil. Evidencia-nos, ainda, a delicada tarefa de instituições e estudiosos que, no processo de identificação de comunidades quilombolas, correm o risco de instituírem identidades não referendadas pelos sentimentos de pertença e singularização cultural portados pelas comunidades em questão.

Entre os relatos que circundam o surgimento da comunidade do Rodeadouro, detectamos, ainda, a referência mítica à história de um escravizado fugido que, escondendo-se na região, teria tomado uma elevação rochosa como moradia. Chamada de aloque ou aloquê, pronúncia ainda sem consenso na comunidade, a pedra que teria abrigado o fundador do Ro-

\footnotetext{
${ }^{5}$ Uma das figuras mais animadas durante as apresentações do Samba, D. Fátima, coordena, juntamente com D. Sueli, a distribuição das bebidas na roda, garantindo que todos os participantes estejam servidos. Após ser sucessivamente requisitada para ofertar informações sobre as manifestações de sua comunidade, decidiu tomar o Samba como objeto de estudo para o Trabalho de Conclusão de Curso de sua Graduação em Pedagogia, ainda em curso. Desta forma, durante nossas valiosas entrevistas e conversas, ofertou-nos, de forma franca, informações preliminares de sua pesquisa. Entrevista filmada e fotografada - Juazeiro-BA, 2012.
} 
deadouro, ao ser pisada, produziria um som diferenciado das demais, sendo utilizada atualmente como ponto de partida dos penitentes da comunidade.

Sendo iniciada do aloque/aloquê e de poucas casas de alvenaria, a comunidade do Rodeadouro atualmente possui cerca de 700 moradores, que habitam construções de variados tipos; com parte significativa das ruas calçadas, água encanada, rede de esgoto, abastecimento de energia elétrica, serviço de telefonia residencial e móvel, internet, estrada de acesso asfaltada e oferta, mesmo que limitada, de transporte público. Os serviços de saúde pública, contudo, são prestados pelo posto de uma comunidade vizinha, Lagoa do Salitre, localizada a $6 \mathrm{~km}$ do Rodeadouro. Também nesta comunidade, são ofertados os ensinos Fundamental II e Médio.

Mesmo para aqueles com formação escolar, a estrutura da comunidade oferece poucas possibilidades de emprego, forçando jovens a morarem no centro da cidade ou a promoverem a migração pendular em busca de oportunidades de engajamento no mundo do trabalho. Segundo o Sr. Antônio, a comunidade, que antigamente se dedicava à agricultura, pesca e pecuária, sobrevive atualmente de trabalhos externos ou de atividades do turismo local.

A importância econômica do turismo para os moradores da comunidade também pode ser observada no seu cotidiano. Possuindo a única travessia da cidade para a Ilha do Rodeadouro, um dos pontos turísticos mais visitados da região, a comunidade tem se dedicado à recepção comercial do turista. Durante a semana, passa pela comunidade um pequeno quantitativo de visitantes, não exigindo grande suporte além de bares, restaurantes, pequena estrutura de hospedagem e estacionamento, já fixos. Aos finais de semana e feriados, contudo, a recepção é iniciada no ponto de ônibus central, com a montagem de banquinhas de doces, petiscos, água, cerveja, refrigerante, cangas, óculos e acessórios em geral. Nestes dias, o quantitativo de barquinhas e de pessoas escaladas para trabalhar na travessia também aumenta, para garantir uma maior celeridade ao processo.

No cair da tarde dos finais de semana e feriados, em especial nos domingos, as últimas embarcações, sempre lotadas, trazem turistas ainda sedentos de diversão que, juntamente com alguns moradores, transformam a comunidade em orla de eventos. Nestes dias, mesmo de longe, é possível escutar a diversidade de ritmos executados nos bares que ficam na área de embarque e desembarque, alguns com shows e música ao vivo. Desta forma, o fluxo de turis- 
tas se mantém intenso até os últimos horários do serviço de transporte público, quando a comunidade retorna às suas cotidianamente ventiladas, pacatas e silenciosas noites.

Em épocas de Reisado, no entanto, o cotidiano noturno da comunidade também é alterado. O costumeiro silêncio semanal é rompido pelo toque do tamborete; as ruas, sempre vazias, são ocupadas por cortejos de crianças, jovens, adolescentes, adultos e idosos; as casas, fechadas em sua maioria, se abrem para receber os vizinhos e amigos; os tons amarelados das fotografias cedem lugar ao colorido movimento do samba.

\section{OH! ME ABRA A PORTA, OH! SINHÁ Ê!}

Desterritorializado pelos navios portugueses, o reisado - uma referência à narrativa bíblica na qual os três Reis Magos, guiados pela estrela de Belém, fazem uma visita ao menino Jesus logo após seu nascimento - foi absorvido pelo catolicismo popular brasileiro, que lhe conferiu uma diversidade de ritmos e rituais, variantes de acordo com as influências e características festivas de cada localidade. Desta forma, no período atribuído às comemorações natalinas, de 24 de dezembro a 6 de janeiro do ano seguinte, são realizados, em diversas partes do Brasil, festejos dedicados aos Reis Magos, genericamente conhecidos como reisado (OLIVEIRA, 2010).

Na região e na circunvizinhança das cidades de Petrolina-PE e Juazeiro-BA, no submédio São Francisco, já foram identificados vários focos, com diferentes formas, períodos e práticas de Reisado. Na comunidade campo de pesquisa, assim como em outras que lhe são próximas, os festejos de Reisado começam habitualmente nos primeiros dias do ano, prolongando-se até que todas as casas da comunidade sejam visitadas, respeitando-se, contudo, os casos nos quais o dono da casa, de forma implícita ou explicita, demonstre seu não interesse em receber o cortejo do Reisado, seja por motivo de doença, morte, credo ou situação financeira.

Sobre o surgimento da manifestação no Rodeadouro, tivemos contato com algumas hipóteses. Defedendo a ideia de reminiscência quilombola, o Sr. Antonio6 argumenta que a

\footnotetext{
${ }^{6}$ Tendo nos abordado durante a saída da Bandeira do Divino na comunidade, o Sr. Antônio, que não participa do cortejo do Reisado nem das apresentações do Samba da comunidade, mas faz parte do Samba de Véio da
} 
própria fabricação dos instrumentos utilizados é característica de culturas quilombolas do Brasil. Trazendo uma visão mais conceitual, D. Ovídia tece uma ligação entre cultura popular e religiosidade, definindo o Samba como um complexo cultural herdado das três raças tomadas na historiografia brasileira como base para a constituição cultural do país. Trazemos um trecho de sua fala para exemplificar:

O samba mesmo vem dos índios, então, é alguma coisa ligada aos índios, o batuque e o sambar. E o batuque, também, é das pessoas que trabalhavam e navegavam no São Francisco e aí, dali, tiravam, durante a noite, para sambar com os próprios instrumentos que existia lá, por isso que o batuque vem do negro. E as músicas que a gente canta no samba hoje, assim, dizem os historiadores que vem de Portugal. Então, por isso que tem as três raças, o índio, o negro e o branco. Então, tem uma mistura o samba de véio, né?

Permitindo-nos entrever reflexos das histórias sociais conformadas sobre o samba no Brasil, a fala de D. Ovídia, em certo ponto, lembra-nos a defesa do Dossiê (IPHAN, 2006) sobre o caráter mestiço do samba de roda do Recôncavo baiano, em especial, quando referenda as letras dos sambas cantados. A afirmação de que o "samba mesmo" teria vindo dos índios, por sua vez, nos remete à tese defendida por Bernardo Alves Filho (2002) e acolhida por alguns pesquisadores do samba no Sertão nordestino, de que o samba seria uma manifestação "brasilíndia", ou seja, teria suas bases no complexo cultural indígena. Em seguida, D. Ovídia retorna ao batuque construindo uma relação entre o surgimento do samba de véio e o cotidiano laboral de negros que exerciam atividades profissionais no Rio São Francisco. A síntese de sua fala, contudo, é categórica: o samba de véio do Rodeadouro é constituído pelas três raças, o índio, o negro e o branco.

Apontando a manifestação como uma festividade emergente do cotidiano de trabalhos dos primeiros habitantes do Rodeadouro, D. Fátima nos conta que os contemporâneos de seus tataravôs, juntamente com moradores de uma comunidade vizinha, se utilizavam de versos e cantorias para tornar as atividades na casa de farinha e na pesca menos enfadonhas.

comunidade vizinha, a Ilha do Massangano, nos traz uma visão mais externa das manifestação em estudo, pontuando, muitas vezes, aspectos gerais para explicação de questões específicas. Entrevista filmada - JuazeiroBA, 2012. 
[...] Na pescaria ou nas festas da mandioca, que era pra raspar nas casas de farinha, né?, e eles já faziam isso daí... então eles, pra não passar, assim... uma coisa monótona, e não tinha som, eles, com os materiais de trabalho, já faziam sua festa. Bem assim eram os pescadores, iam chegando lá, enquanto o peixe estava ali cozinhando, eles estavam lá, cantando, tirando uns versos, para ver se passava o horário para até então... fazer a culminância. Tinha a cachaça e tinha a comida, então eles faziam esse processo aí.

A realização do Reisado no mês de janeiro, por sua vez, teria surgido da necessidade de se visitarem uns aos outros, uma vez que, com o crescimento da comunidade, várias casas foram surgindo. De forma geral, contudo, as manifestações são sempre lembradas como herança de gerações passadas, ou, como costumam dizer, dos mais velhos, dos mais antigos, sem restrições a grupos familiares.

Descrevendo a manifestação na comunidade, D. Ovídia nos explica que para a realização do Reisado:

Tem que ser um grupo, não pode ser uma pessoa só para tirar um reisado. Tem que ter as pessoas para dançar, bater palmas, tem pessoas pra bater o tamborete, pandeiro, triângulo. Como é que faz... se reúne na porta de uma pessoa; essa casa tem que estar com a porta fechada, e a gente canta o reisado com a porta fechada, aonde tem uma parte no final do reisado que manda o dono da casa abrir a porta.

Desta forma, e respeitando as restrições pontuadas acima, várias casas são saltadas, não recebendo a visita do cortejo. Naquelas em que o Reisado é realizado, o procedimento é sempre semelhante. Posicionados em frente à casa, que mantém a porta fechada, um coro acompanhado por um grupo percussivo, canta em duas vozes:

Oh! de casa, nobre gente

Escutai o que eu direi

Ô partir do oriente

A chegada dos três reis

Os três reis quando souberam

Que era nascido o messias

Montaram em seus cavalos

Com prazer e alegria

É com a virgem Maria

Recebei seu bento filho

O primeiro trouxe ouro

Para seu trono ourar

$\mathrm{O}$ segundo trouxe incenso 


\author{
Para seu trono incensar \\ O terceiro trouxe mirra \\ Pra saber se emortar \\ Bateu asa, cantou galo \\ Onde o salvador nasceu \\ Canta os anjos nas alturas \\ Gloria e recebe Deus \\ (Música cantada no Reisado do Rodeadouro).
}

Breve narrativa da visita dos Reis Magos ao menino Jesus, esta parte da música, com cerca de dois minutos, é sempre cantada com a porta fechada, tendo o dono da casa, ou um representante do mesmo, no seu interior. Em muitos casos, ao verem a aproximação do cortejo, os moradores entram em suas casas e fecham a porta, sinalizando que estão preparados para receber o ritual. Na segunda parte da música, o coro solicita ao dono da casa que abra a porta, recebendo aqueles que, vindo de longe, querem vadiar!

Oh! Me abre a porta, oh! Sinhá ê!

Que eu quero entrar, oh! Sinhá ê!

Eu venho de longe, oh! Sinhá ê!

Quero vadiar, oh! Sinhá ê!

(Música cantada no Reisado do Rodeadouro).

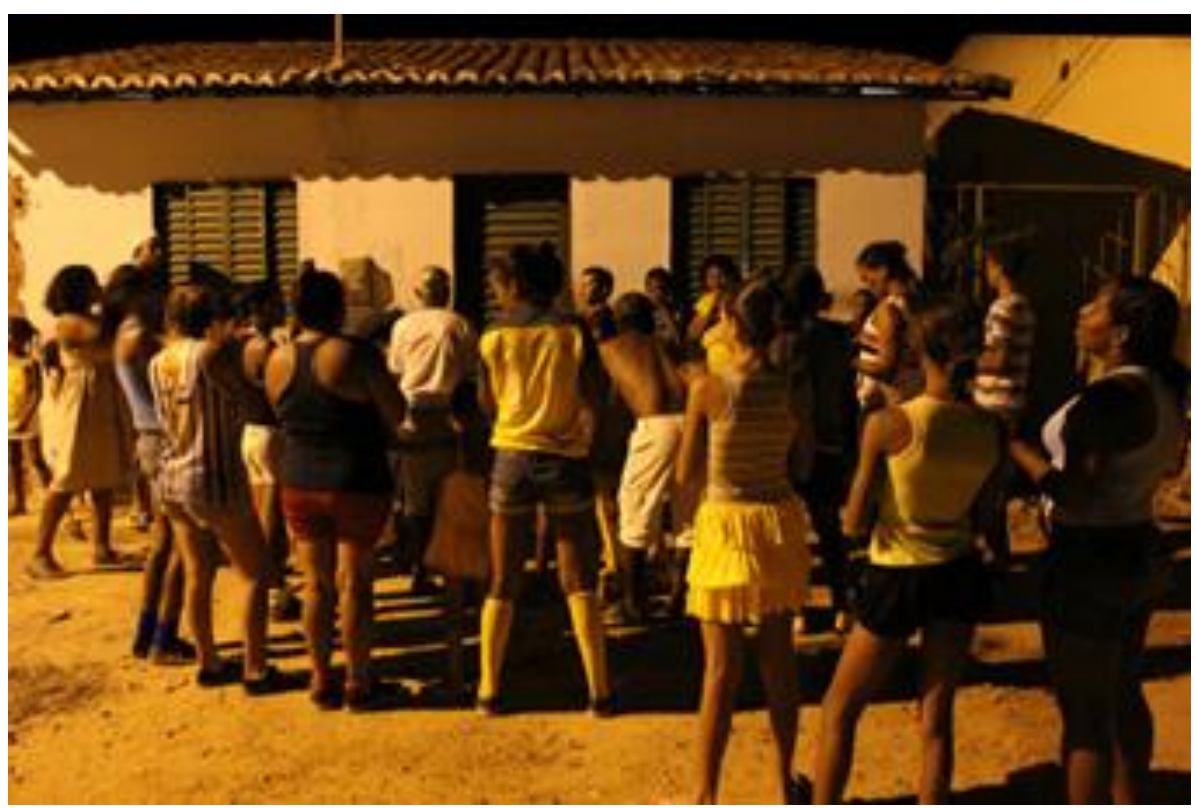

Imagem 1: Ritual do Reisado cantado com a porta fechada - Comunidade do Rodeadouro, Juazeiro-Bahia, $2012^{7}$

${ }^{7}$ Todas as fotos utilizadas neste artigo são de autoria de Juarez Rocha Junior. 
Com a abertura da porta, a saudação, Viva Santo Reis ao dono da casa!, marca o fim do rito religioso, cedendo espaço para o momento festivo do Reisado do Rodeadouro. Respondendo à pergunta “Samba ou Lamba?", o dono da casa opta por ter, ou não, realizado o samba nas dependências de seu domicílio. Se a resposta é negativa, o cortejo segue em frente, dirigindo-se a outras residências.

Ao contrário, com a solicitação da realização do Samba, resposta festejada pelo cortejo, rapidamente se forma uma roda na calçada, quintal, sala ou qualquer espaço da casa, apontado pelo dono. O samba, na grande maioria das vezes que pudemos observar, foi iniciado com uma música de saudação ao dono da casa, fosse com o simples refrão "Ao dono da casa, boa noite / Boa noite, boa noite" ou com a música Ô Dono da Casa, uma referência à oferta de alimentos e bebidas, em especial a cachaça, que deve ser praticada pelo dono da casa que recebe o Samba:

\section{Ô dono da casa, Ele é bom, ele dá! Ô se não hoje, Amanhã ele dá!}

A partir de então, as músicas seguem sem ordem definida. Com inspirações diversas, as letras falam: do cotidiano de uma comunidade rural; de elementos ribeirinhos; de aspectos mítico-religiosos; de despedidas, viagens e movimentos migratórios, com destaque para os realizados através de grandes embarcações fluviais; de relações sociais, econômicas, de gênero, raciais e, mesmo, policiais; e, como já era de se esperar, do próprio samba.

Composto basicamente por três tamboretes, um triângulo e um pandeiro - instrumentos que fazem rodízio nas mãos daqueles que se dispõem a executá-los, em especial os jovens do sexo masculino da comunidade -, o grupo percussivo que acompanha o coro do Reisado e realiza o Samba recebe o complemento das palmas dos participantes e espectadores. 


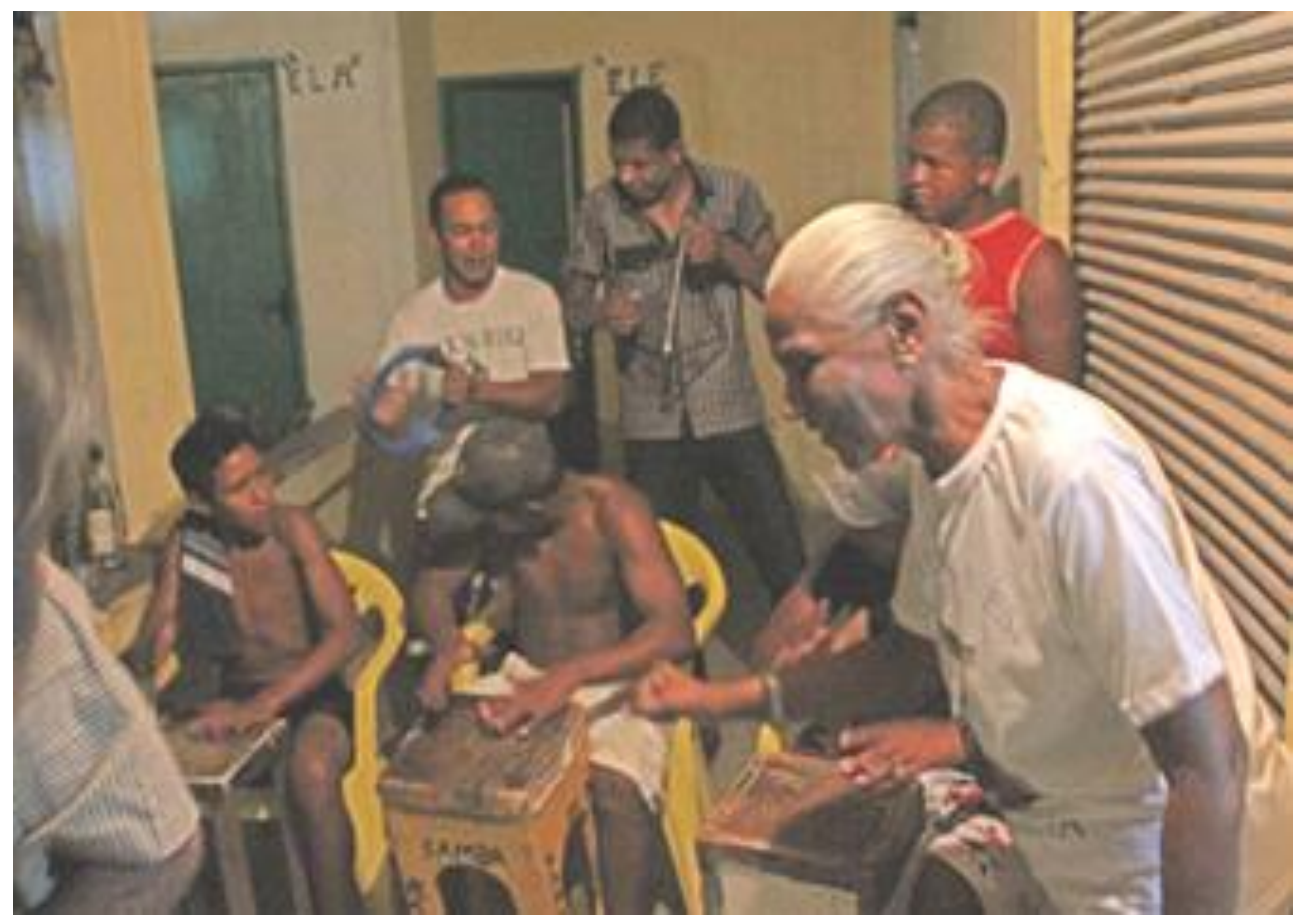

Imagem 2: D. Ovídia e grupo percussivo marcando o compasso - Comunidade do Rodeadouro, Juazeiro-Bahia, 2012.

Nas apresentações realizadas fora da comunidade, o samba recebe o acompanhamento de uma guitarra elétrica, executada por um senhor que, não residindo no Rodeadouro, é convidado para apresentações pontuais. Demasiadamente alta, a guitarra concorre com os instrumentos percussivos e com a primeira voz do samba feita, algumas vezes, sem o auxílio do microfone. Sobre esta questão, D. Fátima relata que

antigamente, dizia que quem acompanhava era uma viola. "Um violão", antigamente que a gente chamava de "viola". Mas, no que surgiu a Associação, eles viram a necessidade de botar uma viola. Mas nós não encontramos essa pessoa que tocasse essa viola... por que a guitarra já é um instrumento bem avançado... já é uma tecnologia grande e, particularmente, eu não gosto. Eu acho que, com a viola, ela tem um som totalmente diferente, né? Com a guitarra, parece que o som estronda e a gente fica se acabando de gritar, porque ele se torna alto, né? Mas era um instrumento... que era tocado só com a viola, não era com a guitarra (grifo nosso).

Tomada de forma figurativa, a viola, neste contexto, representa a necessidade surgida, após o processo de composição da Associação do Samba, da presença de um instrumento cordofone entre os tamboretes, pandeiros e triângulo do Samba de Véio do Reodeadouro. O pro- 
Pontos de Interrogação, v. 3, n. 2, jul./dez. 2013

Revista do Programa de Pós-Graduação em Crítica Cultural

Universidade do Estado da Bahia (UNEB), Campus II - Alagoinhas - BA

cesso de organização da Associação, por sua vez, nos foi melhor detalhado por D. Fátima, que relata a atuação do Sr. Hélio Gomes, consultor e instrutor do Programa Produzir, desenvolvido pelo Governo Federal, em parceria com o Serviço Nacional de Aprendizagem do Comércio (SENAC/BA).

[...] Ele trouxe essa aula. Todos os integrantes que participavam foram levados para lá, e aí ele foi falando e a gente ouvindo. Quando chegava ao final da aula, a gente ficava conversando entre si: ele falou uma coisa certa. E foi juntando uma coisa com a outra. Quando acabou a reunião e o período da aula, que era uma semana, aí surgiu a necessidade [de criação da Associação]. Aí ele disse: 'Se precisar de mim, eu volto para dar toda aquela ajuda necessária'. E assim ele fez: ele veio, passou para todos: 'É necessário ter isso, conhecer e tudo'. E fizemos! Logo de ponta, escolhemos uma pessoa para que ela ficasse de ponta para fazer toda aquela [tramitação da] papelada e, também, ter uma pessoa de frente para que ele... a comunicação, os eventos... e cada uma tinha o seu papel.

Desta forma, através da ação externa - representada, na fala de D. Fátima, pelo pronome eles, sujeitos que viram a necessidade, em oposição ao pronome nós, agentes da tentativa de inserção do violão no Samba de Véio - é constituído o imperativo de um instrumento cordofone para o "Samba de Véio do Rodeadouro" que culmina, diante da impossibilidade do violão, na adoção de uma ruidosa guitarra. A não presença do instrumento nas rodas - realizadas pela comunidade e para a comunidade -, contudo, depõe sobre a sua não essencialidade. A restrição da sua presença a apresentações públicas, por sua vez, denota o esforço dos praticantes do "Samba do Rodeadouro" para constituírem um produto artístico aproximado do modelo que lhes foi apresentado como ideal, o que poderia facilitar sua legitimação e inserção na cadeia de circulação e consumo de bens culturais.

Demarcando diferenças, alguns elementos apontam para uma relação modeladora entre o Samba do Rodeadouro e as prescrições da indústria cultural e das políticas patrimonialistas do Estado brasileiro e baiano. Nesse contexto, o próprio ato de constituição da Associação Cultural Samba de Véio do Rodeadouro pode ser compreendido como uma forma de iniciação à profissionalização do grupo. Facilitando, dentre outros, a concorrência em editais de apoio, a recepção de doações e a organização política dos praticantes, a composição de pessoa jurídica retira a manifestação do âmbito exclusivamente comunitário e cotidiano para inseri-la numa lógica de mediação do capital. Diferenciando-se da prática interna em que o valor de troca 
não guarda distanciamento do valor de uso, o samba ganha, além da guitarra, alguns outros instrumentos, figurinos e preocupações estéticas na organização da roda e na execução do samba quando realizada para um público externo.

Os figurinos, assim como alguns instrumentos musicais, foram adquiridos com os recursos de um projeto proposto pela Associação Cultural Samba de Véio do Rodeadouro e selecionado pelo Edital de Apoio a Microprojetos Mais Cultura. Suas inserções nas apresentações do samba, contudo, são anteriores a este Edital. De acordo com D. Maria8, no ano 2000, a comunidade, assim como outras próximas ao Rodeadouro, recebeu - do Sistema S de Ensinouma turma de Educação de Jovens e Adultos (EJA), da qual ela fazia parte.

Como uma das atividades deste curso, foi proposta:

A cada comunidade levar sua manifestação cultural (de sua comunidade). Aí, eu disse: 'Professora, eu já sei o que a gente vai levar'. Eu que inventei. [...] 'Professora, vamos levar o samba'. Aí a gente combinou na escola: "vamos mudar, vamos comprar umas roupas pra gente ir diferente". Aí, a gente comprou uma chita estampada, e fizemos só a saia comprida. Dissemos: "todo mundo de blusa branca, pra ficar tudo igualzinho". Pelo menos a cor, não era o modelo, mas a cor era igual. Aí, a gente foi. [...] Quando chegou lá, que esse samba se apresentou, Ave Maria! Foi um sucesso!

Padronizando o grupo que se apresenta, o figurino cumpre a evidente função de distinguir o público e os performances. Guardando uma lógica de consumo, o Samba de Véio é constituído como produto artístico que se apresenta para um público espectador, substituindo a relação entre anfitrião e visitantes, estabelecida durante o reisado da comunidade. O que é seguido, na descrição feita por D. Maria, pelo início da cobrança de cachês, em algumas apresentações. Afinal de contas, o samba tem uma estrutura, mesmo que mínima, a ser mantida, além de alguns cachês individuais a serem pagos. (Quando há a necessidade de alguns dos participantes, na maioria das vezes os percussionistas, faltarem um dia de trabalho para parti-

\footnotetext{
${ }^{8}$ Presidente da Associação Cultural Samba de Véio do Rodeadouro, D. Maria tem papel destacado no processo de organização e formalização do Samba da comunidade. Sua participação nos eventos, contudo, tem sido limitada por um problema de coluna adquirido em um acidente de trabalho. Gentil e sempre disposta a ajudar, D. Maria foi basilar para o nosso segundo momento de observação, quando alugamos uma de suas casas, vizinha à que atualmente ela ocupa. Entrevista filmada - Juazeiro-BA, 2012.
} 
ciparem de uma apresentação externa do Samba de Véio, a Associação paga um cachê correspondente à diária, evitando prejuízos pessoais).

\author{
Sai, sai, sai, ô piranha! \\ Sai da lagoa, piranha, \\ Bota a mão na cabeça, piranha, \\ Tira bota nas cadeiras, ô piranha, \\ Dá um jeitinho no corpo, ô piranha, \\ Dá uma umbigada na outra, ô piranha! \\ (Sai, Piranha)
}

Na maioria dos sambas intitulados "de roda", cuja apresentação já pudemos presenciar, os tocadores, alguns sentados e outros de pé, são tomados como referência para a composição da roda: é em função deles que se distribuem os cantadores, os dançadores do grupo e o público que, a partir da interatividade proposta, vez por outra, se transforma em participante ativo da apresentação. Ao centro da roda percebe-se tacitamente a convenção de que estejam os dançarinos, em solo ou aos pares, que, ao final de suas apresentações, devem convidar outra pessoa a tomar seu lugar, mantendo-se, desta forma, o processo de revezamento.

No samba do Rodeadouro, assim como na música que por ora nos serve de epígrafe, a umbigada - que em suas extensões ressignificadas pode ser tanto dada no ar com gestos rápidos do corpo, quanto com simples toque de mãos - é utilizada para convidar a nova pessoa a integrar a roda. Este movimento que se propõe contínuo é, no entanto, intercalado pela necessidade de organização da roda. Ansiosos por estarem no centro do círculo, os dançarinos mirins, bem como o público que a tudo quer acompanhar, acaba, por vezes, afunilando a roda, transformando-a em um aglomerado de várias camadas sobrepostas. Nas apresentações externas, no entanto, mesmo com vasto público e a presença de muitos integrantes, dentre eles quantidades significativas de crianças, a roda comumente se mantém bastante aberta. 


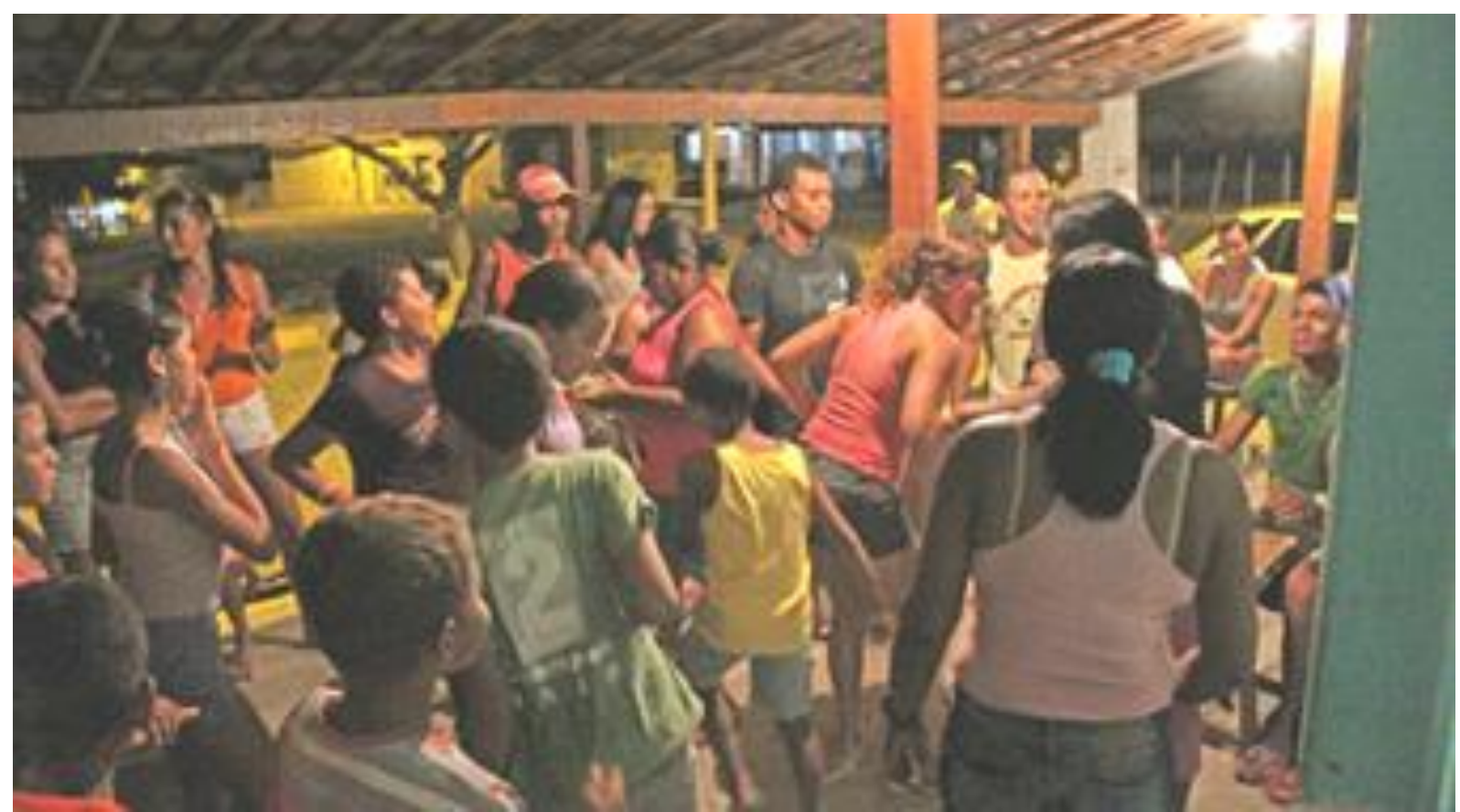

Imagem 3: A roda, totalmente ocupada, do Samba de Véio - Comunidade do Rodeadouro, JuazeiroBahia, 2012

Temos, desta forma, que apresentações para públicos externos à comunidade ensejam a necessidade de manutenção da roda aberta, ao passo que, na prática interna do samba, mesmo com a tentativa de algumas componentes, a roda não mantém um padrão organizacional. Esta questão, contudo, é melhor exposta por D. Fátima, no diálogo transcrito abaixo, quando nos responde sobre as modificações operacionalizadas na manifestação após a constituição da Associação.

Quercia Oliveira: Nesse processo de construção do grupo, o que mudou, ou então... houve ou não mudança?

D.Fátima: De haver, houve, porque onde você saía com seus próprios instrumentos e você não tinha uma roupa adequada para você vestir... e aí, quando surgiu a necessidade de fazer uma roupa, aí ficava: 'Qual a roupa que vai?' Quando iniciou, não: que só tinha aquela, a gente só saía com aquela... Mas, assim, a gente não tinha essa preocupação de estar todo mundo numa roda, saía todo mundo, de uma certa maneira. Você teve aqui presenciando o São Gonçalo que depois a gente sambava. Era praticamente daquele jeito que a gente fazia antigamente. A roda era mínima e entrava quem queria, a gente não tinha esse negócio de ah... puxava um, não! A gente era, entre os novos e os velhos, que acompanhassem, se acompanhavam, né?, que os pais não gostavam de levar por que não tinha horário de terminar... E aí, quando se surgiu agora com o fardamento, é totalmente diferente, porque a 
gente tem que estar no ritmo do batimento, a gente não tinha esse negócio do toque da mão, só era umbigada, né? E, praticamente, quando a gente vai estar lá no grupo, a gente tem que ter uma roda, pra que, nem só nós que fazemos parte do grupo, mas toda pessoa, a clientela, que esteja presente, que ele faça todo esse trabalho, né? - de participar da roda.

Realmente inquietante, esse depoimento nos traz dois elementos reveladores: a significação da roda e a ressignificação da umbigada. Com o intuito de tornar o convite a fazer parte da roda menos intimista, possibilitando a inserção do público ou mesmo da clientela, como apontou D. Fátima, a umbigada, que antes consistia em um rápido toque entre umbigos, como o nome sugere, foi transposta para qualquer parte do corpo, inclusive as mãos. Tornando o Samba de Véio mais vendável, a ressignificação da umbigada nos dá indícios sobre os processos de higienização e moralização pelos quais passam as manifestações culturais de caráter popular quando em contato com a indústria cultural. Afinal de contas, como aponta Antonio Augusto Arantes, é preciso enxugar

[...] os eventos artísticos denominados populares, de características consideradas inadequadas ou desnecessárias sob o pretexto de revelar-lhes mais claramente a estrutura subjacente. $O$ resultado de procedimentos desta natureza, entretanto, é o de higienizar esses eventos, ocultando os seus aspectos de pobreza, o seu caráter tosco e, aos olhos de muitos, grosseiros. (1998:20).

Sobre a significação da roda, por sua vez, traçamos uma relação mais próxima ao processo de patrimonialização do samba de roda do Recôncavo. Mesmo sendo tomado como formato figurativo, a roda do samba patrimônio é sempre representada pelo Dossiê do Samba de Roda do Recôncavo como ampla, aberta e pronta para acolher, de forma ordeira e organizada, os pretendentes sambistas (IPHAN, 2006). Assim, este formato se estabeleceu como um padrão a ser reproduzido pelas demais manifestações que guardam proximidade com, ou que são nomeadas como "samba de roda". Também influenciado por este modelo, na época em fase de conformação, o Sr. Hélio sugere à comunidade e aos praticantes do samba modificações que, aparentemente pequenas, acabam engendrando um processo de ressignificação e de padronização do Samba de Véio do Rodeadouro - em prol da revivificação de um modelo patrimonializado, levando-nos a questionar sob quais outras formas, além da que conhecemos, 
poderia se apresentar o Samba do Rodeadouro e tantos outros que estão, sempre, tentando se organizar em roda?

Constituído como o uno - padronizador - o samba patrimônio tem sido tomado como exemplo para a organização estética e artística de manifestações que lhe guardam proximidade. É desta forma que consultores e mediadores externos têm sugerido modificações e implementações nos batuques de várias comunidades, constituindo-os como produto artístico a serem festejados. Indício de nosso atual regime patrimonialista, a seleção operada no presente para a constituição de nossos futuros passados tem estabelecido relações problemáticas com a indústria cultural e o sistema capitalista, circunscrevendo nossas relações com nossas manifestações patrimônios a uma lógica fetichista de consumo. Concomitantemente, a ausência de políticas públicas - para as comunidades de tradição oral - tem sido refletida nos processos de descontinuidade e rupturas das redes de transmissão dos saberes, necessários à continuidade das manifestações culturais, como pudemos observar no nosso campo de pesquisa.

Constituindo-se como margem de resistência, no entanto, o Samba de Véio do Rodeadouro tem construído entre-lugares e fronteiras de ressignificação de seus fazeres e sambares. É assim que, no samba feito na comunidade, pela comunidade e para a comunidade, os figurinos não são adotados; a amplificada guitarra não é utilizada, as rimas e improvisações, vez por outra, reaparecem; a roda, pungente, ganha indisciplinadas formas, e seu centro um não controlado número de pessoas; e a festa, uma duração indeterminada.

Assim, utilizando-nos da imagem construída por Callado ${ }^{9}$, reportamos-nos ao questionamento feito no início deste artigo, podemos perceber o Estado e sua política patrimonialista como as onças, os agentes da violência homogeneizadora. Desta forma, o Samba de Véio do Rodeadouro também é jabuti: das distinções pronominais; das opiniões de concordância e discordância confidenciadas; dos relatos que reconstroem os processos de parada, retomada e profissionalização do samba; da desconfiança com pesquisadores e acadêmicos; da participação em editais públicos de apoio; da manutenção do ritual do reisado mesmo em apresenta-

\footnotetext{
${ }^{9} \mathrm{O}$ jabuti que só possuía uma casca branca e mole deixou-se morder pela onça que o atacava. Mordeu tão fundo que a onça ficou pregada no jabuti e acabou por morrer. Do crânio da onça o jabuti fez seu escudo (apud Santiago, 2000:9).
} 
ções externas; do tamborete tocado e da umbigada batida; de tudo isto, ele tem feito seus escudos e armas de guerra.

\section{REFERÊNCIAS}

ADMINISTRAÇÃO DA HIDROVIA DO SÃO FRANCISCO - AHSFRA. Institucional. Disponível em: <http://www.ahsfra.gov.br/?op=conteudo\&id=133\&menuId=165>. Acesso em: 27 ago. 2012.

ALVES FILHO, Bernardo. A pré-história do samba. Petrolina: Prefeitura de Petrolina, 2002.

ARANTES, Antonio Augusto. O que é cultura popular. São Paulo: Brasiliense, 1998.

BRASIL. Decreto $n^{o} 3.551$, de 4 de agosto de 2000. Institui o Registro de Bens Culturais de Natureza Imaterial que constituem patrimônio cultural brasileiro, cria o Programa Nacional do Patrimônio Imaterial e dá outras providências. Brasília, DOU, 7 ago. 2000. Disponível em: <http://www.planalto.gov.br/ccivil_03/decreto/D3551.htm>. Acesso em: 27 out. 2010.

CARMO, Raiana Alves M. Leal do. A política de salvaguarda do patrimônio imaterial e os seus impactos no samba de roda do Recôncavo baiano. Dissertação de Mestrado em Música, Programa de Pós-Graduação em Música/UFBA, Salvador, 2009.

GOMES, Hélio. Relatório. Juazeiro: o autor, 2006.

HALL, Stuart. Da diáspora: identidades e mediações culturais. Organização Liv Sovik. Tradução Adelaine La Guardia Resende et al. Belo Horizonte: Ed. UFMG; Brasília: UNESCO, 2003.

INSTITUTO DO PATRIMÔNIO HISTÓRICO E ARTÍSTICO NACIONAL - IPHAN. Dossiê IPHAN 4: Samba de Roda do Recôncavo Baiano. Brasília: IPHAN, 2006. Disponível em: <http://portal.IPHAN.gov.br/portal/baixaFcdAnexo.do?id=723>. Acesso em: 30 ago. 2011.

INSTITUTO DO PATRIMÔNIO HISTÓRICO E ARTÍSTICO NACIONAL - IPHAN. $P a$ trimônio Cultural Imaterial: para saber mais. 3. ed. Brasília: IPHAN, 2012.

LIMA, Ari. Tradition, history and spiral of time in the Samba de Roda of Bahia. In: TILLIS, Antonio D. (Org.). (Re)considering blackness in contemporary afro-brazilian (con)texts. New York: Peter Lang Publishing, 2011, v. 1, p. 27-45.

LIMA, Ari. A experiência do samba na Bahia: práticas corporais, raça e masculinidade. Brasília, 2003. Tese (Doutorado em Antropologia Social) - Departamento de Antropologia, Universidade de Brasília, Brasília, 2003. 
NOBRE DE SOUZA LIMA, Cássio Leonardo. Viola nos sambas do Recôncavo baiano. Dissertação (Mestrado em Música) - Escola de Música, Universidade Federal da Bahia, Salvador, 2008.

OLIVEIRA, Quercia. Trajetórias no Massangano: dos festejos de Reis ao Samba de Véio. Monografia (Licenciatura em História) - Departamento de História, Universidade de Pernambuco, Petrolina, 2010.

OLIVEIRA, Quercia. Ecos de Viola no Samba de Tamborete: Jabutinagens às margens do São Francisco. Dissertação (Mestrado em Crítica Cultural) - Departamento de Educação, Colegiado de Letras, Universidade do Estado da Bahia, Alagoinhas, 2013.

SANTIAGO, Silviano. Uma literatura nos trópicos: ensaios sobre dependência cultural. 2. ed. Rio de Janeiro: Rocco, 2000.

SANTOS, Jocélio Teles dos. O poder da cultura e a cultura no poder: a disputa simbólica da herança cultural negra no Brasil [online]. Salvador: EDUFBA, 2005.

\section{FONTES}

ENTREVISTAS REALIZADAS

D. FÁTIMA. Entrevista filmada e fotografada. Juazeiro-BA, 2012.

D. MARIA. Entrevista filmada. Juazeiro-BA, 2012.

D. OVÍDIA. Entrevista filmada e fotografada. Juazeiro-BA, 2012.

DANIELLE LISBOA. Entrevista não gravada. Juazeiro-BA, 2012.

SR. ANTONIO. Entrevista filmada. Juazeiro-BA, 2012.

Recebido em: 14 de novembro de 2013.

Aprovado em: 06 de dezembro de 2013. 